\title{
Optimization Design Method of PSS Based on GA and QFD
}

\author{
Zhang Jianmin, Zhou Jun, Liang Hui \\ College of Mechanical Engineering, Shanghai University of Engineering Science, Shanghai, China
}

\section{Email address:}

jianminlvld@163.com (Zhang Jianmin)

\section{To cite this article:}

Zhang Jianmin, Zhou Jun, Liang Hui. Optimization Design Method of PSS Based on GA and QFD. Science Research. Vol. 4, No. 5, 2016, pp. 133-140. doi: 10.11648/j.sr.20160405.15

Received: October 19, 2016; Accepted: November 5, 2016; Published: December 8, 2016

\begin{abstract}
Due to sustainable production and consumption, customer-centric business model, increasingly homogenization of products and other factors, manufacturers had to adjust existing design and production mode, making their focus gradually shifted from a single product design and production model to a integration system solution which contains product and serviceto meet the customers' need. Product Service Systemis a new ideal proposed to adapt this strategy shift of Manufacturer Company. In this paper, proposing the optimization design method of Product service system based on Quality Function Deployment (QFD) and Genetic Algorithms (GA) to solve the problem as normative in design process, unity in design result and other problems.
\end{abstract}

Keywords: Product Service System (PSS), Optimization Design Method, Quality Function Deployment (QFD), Genetic Algorithms (GA)

\section{Introduction}

The concept of product service system, also named as "functional sales" [1], or "functional products" [2], was proposed by the United Nations Environment Program (UNEP) in the late 1990s. Its core idea is to provide "products" and "services", meeting customer' requirements while reducing resource consumption and environmental impact at the same time.

In traditional manufacturing modes, manufacturers usually pay more attention to the attribute of product itself in order to through product sales to earn more money and increase their market share [3]. They seldom concentrate on products' end-of-life, which usually results in waste of limited resources and environmental problems. With the approaching of economic globalization and much fiercer competition, more and more manufacturers are considering model transformation, integrating products and services which can not only improve efficiency but also can result in a new design model which is positive for economic and environment.

Since PSS is put forward, lots of scholars have made research on it, mainly concentrated in the following aspects: concept and definition aspects, features and classification aspects, design aspects and application research aspects. Mont [4-5] analyzed the connotation and meaning of PSS, and established the theory of PSS. Tukker [6] lists eight PSS, and analyze each king of PSS qualitatively. Sakao [7] made research on PSS solution design based on t-PSS. Sundin [8] introduced the Swedish enterprises design experience based on PSS.

Up to now, the concept research has been mature, but design method and its supporting technologies still have some problem, for example in design process the standardization from customer demand to design characteristics, design result single and so on. To solve the problems above, this paper proposes the optimization design method research of PSS based on QFD and GA.

\section{Methodology}

PSS design process is similar to the product design process, including task definition, plan design, detailed design and construction design stage. Scheme design in front of the design process, not only is the basis of the detailed design, but also is the important stage of the PSS design. Its main task is to determine reasonable design to meet customers' demand. Scheme design largely determines elements of PSS, such as function, quality and so on. Scheme design occupies 70 percent in PSS design. So this paper from design process aspect and design result aspect to make research on the optimization design method of PSS. Through the method, Solving the standardize problem in design process from customers' demand to technical characteristics, and the 
problem of design result singly.

\subsection{Optimization of PSS Design Process Based on QFD}

In this Study, the optimization design method is based on existing schemes. As now CBR [9] is a famous method to realize scheme design, when achieve customer demand, designer can through case base to find the product scheme which can meet customer demand. So delivery and distribution from customer demand to technical characteristics is very important in CBR.Traditional method to realize the delivery and distribution is QFD [10], but it cannot realize delivery from customer demand to product and service in PSS at the same time. In this paper, improve the QFD method to solve the standardize problem in design process.

House of Quality (HoQ) [11] in QFD is to realize the transmission and distribution of customer demand, it is an important method. HoQthrough the form of relation matrix realize conversion between customer demand and product (service) characteristics, andusing the conversion in design process to complete the design, its typical form as shown in figure 1.

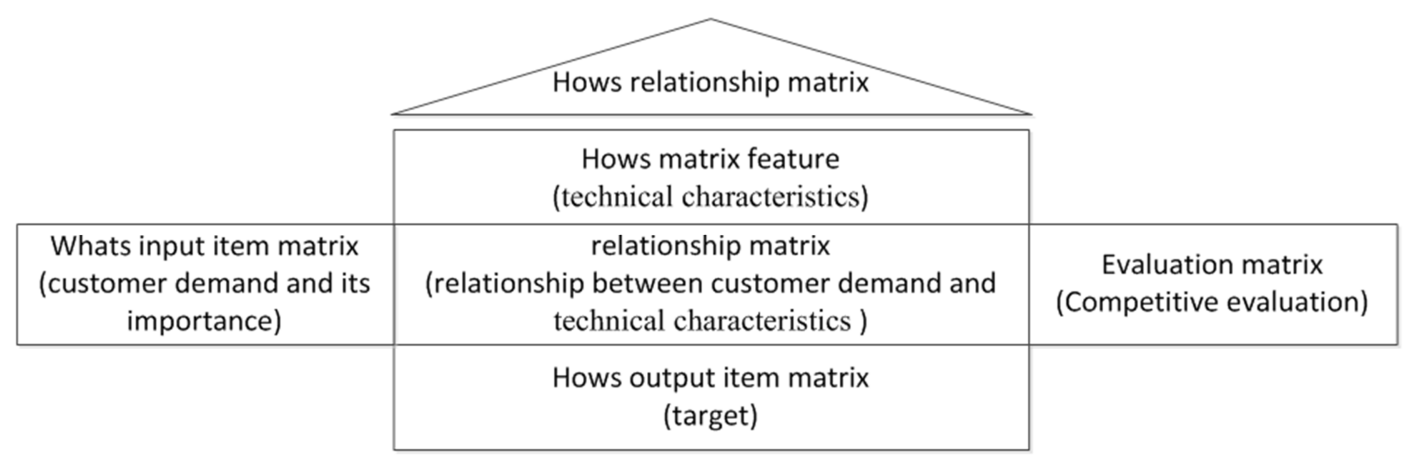

Fig. 1. House of quality.

HoQ is mainly using market research techniques and analysis tools, to determine customer requirements and enterprise resources, and determine the parts of HoQ,including the technical characteristic, the customer demand, customer demand relation matrix, the technical characteristic relation matrix, the plan of the customer requirements matrix, and the technical features design matrix, etc. In order to make the method can be applied to PSS design, transform its form to make it can adapt to PSS design.
Modified HoQ breakthrough the bottleneck of the traditional design, can satisfy the transmission and distribution from customer demand to the product technical characteristics and service technical characteristics at the same time.It mainly includes: customer needs comparison matrix (Fig. 2 left), the customer requirements and technical characteristics relation matrix (Fig. 2 middle), technical characteristic relation matrix ((Fig. 2 above) design and technical characteristics of matrix (Fig. 2 below).

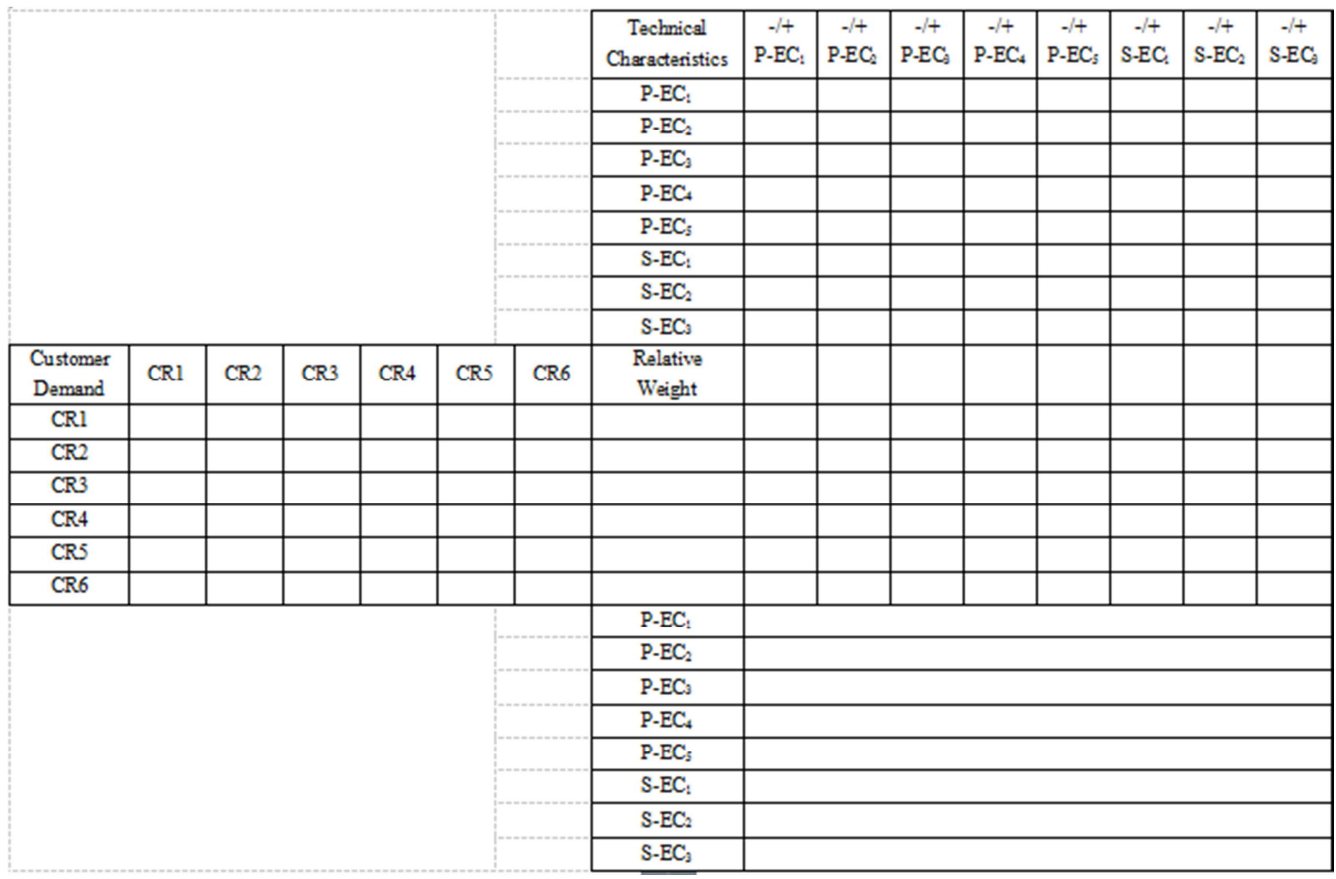

Fig. 2. QFD of product service design. 
HoQ mainly apply Analytic Hierarchy Process (AHP) method to build customers' demand relation matrix, AHP [12] solves problem process as follows.

\subsubsection{Establish Hierarchy Structure Model}

According to the relationship between decision objective, decision factors (decision criterion) and decision-making object,we divided the system into top layer, middle layer and the lowest. At the highest level is the purpose of decision making, the problem to be solved; The middle layer is the problem of the consideration and decision criteria; The lowest layer is for decision-making object design.

\subsubsection{Construct Judgment Matrix}

Judgment matrix shows upperdominatelower thatevery lower relative to the upper level of the importance, It is the same level of pairwise comparison results between the elements. Assuming that $\mathrm{Ai}$ and the next layerof $A_{1}, A_{2}, \ldots A_{n}$ which have relationship with $\mathrm{C}_{\mathrm{i}} \mathrm{in}$ A layer of elements, the structure form of the judgment matrix as shown in table 1 .

Table 1. Structure of judgment matrix.

\begin{tabular}{lllll}
\hline $\mathbf{C}_{\mathbf{i}}$ & $\mathbf{A}_{\mathbf{1}}$ & $\mathbf{A}_{\mathbf{2}}$ & $\ldots$ & $\mathbf{A}_{\mathbf{n}}$ \\
\hline $\mathrm{A}_{1}$ & $\mathrm{a}_{11}$ & $\mathrm{a}_{12}$ & $\ldots$ & $\mathrm{a}_{1 \mathrm{n}}$ \\
$\mathrm{A}_{2}$ & $\mathrm{a}_{21}$ & $\mathrm{a}_{22}$ & $\ldots$ & $\mathrm{a}_{2 \mathrm{n}}$ \\
$\cdot$ & $\cdot$ & $\cdot$ & $\cdot$ & $\cdot$ \\
$\cdot$ & $\cdot$ & $\cdot$ & $\cdot$ & $\cdot$ \\
$\cdot$ & $\cdot$ & $\cdot$ & $\cdot$ & $\cdot$ \\
$\mathrm{A}_{\mathrm{n}}$ & $\mathrm{a}_{\mathrm{n} 1}$ & $\mathrm{a}_{\mathrm{n} 2}$ & $\ldots$ & $\mathrm{a}_{\mathrm{nn}}$ \\
\hline
\end{tabular}

Among them, the $\mathrm{a}_{\mathrm{ij}}$ shows in $\mathrm{C}_{\mathrm{i}}$, $\mathrm{a}_{\mathrm{i}}$ to $\mathrm{a}_{\mathrm{j}}$ relative important degree, usually $a_{i j}$ option $1,2,3 \ldots .9$, and the reciprocal of them, the meaning of the Numbers as shown in table 2 .

Table 2. Scale and meaning of judgment matrix.

\begin{tabular}{ll}
\hline scale & implication \\
\hline 1 & $\begin{array}{l}\text { Compared to two factors, they have the same importance } \\
\text { Compared to two factors, One factor is more important than } \\
\text { another factor slightly. } \\
\text { Compared to two factors, One factor is more important than } \\
\text { another factor obviously }\end{array}$ \\
7 & $\begin{array}{l}\text { Compared to two factors, One factor is more important than } \\
\text { another factor strongly }\end{array}$ \\
9 & $\begin{array}{l}\text { Compared to two factors, a factor than another factor is } \\
\text { extremely important } \\
\text { above two adjacent judgment of values }\end{array}$ \\
$2,4,6,8$ & $\begin{array}{l}\text { Factors I compared to j is the judgment of the } \mathrm{a}_{\mathrm{ij} .} \text { factor } \mathrm{j} \\
\text { compared toi,the compare judgment } \mathrm{a}_{\mathrm{ji}}=1 / \mathrm{a}_{\mathrm{ij}}\end{array}$ \\
\hline
\end{tabular}

\subsubsection{The Level of Single Order and Consistency Check}

Hierarchical single sorting refers to calculate a relative important degree of each element in the hierarchy according to the judgment matrix. Hierarchical single sorting is calculatingthe weight value and eigenvector of judgment matrix A, calculating characteristics of the vector W (normalized eigenvector), $\mathrm{W}_{\mathrm{i}}$ is the weight of corresponding elements. To test the consistency of judgment matrix, need to use consistency judgment form:

$$
C R=C I / R I<0.1 \quad C I=\left(\lambda_{\max }-n\right)(n-1)
$$

The $\mathrm{CI}$ as consistency index, RI as average consistency index. RI values are shown in table 3.

Table 3. Value of RI

\begin{tabular}{lllllllllll}
\hline order & $\mathbf{1}$ & $\mathbf{2}$ & $\mathbf{3}$ & $\mathbf{4}$ & $\mathbf{5}$ & $\mathbf{6}$ & $\mathbf{7}$ & $\mathbf{8}$ & $\mathbf{9}$ & $\mathbf{1 0}$ \\
\hline $\mathrm{RI}$ & 0 & 0 & 0.58 & 0.90 & 1.12 & 1.24 & 1.32 & 1.41 & 1.45 & 1.49 \\
\hline
\end{tabular}

When $\mathrm{CR}<0.1$, the consistency of judgment matrix is satisfied, otherwise,we need to adjust the judgment matrix, make it has satisfactory consistency.

\subsubsection{The Level of Total Sorts and Consistency Check}

After the calculation of relative importance of various elements we can achieve comprehensive importance of each factor relative to the system.

Total sorts consistency check:

$$
\begin{aligned}
& C R=C_{I} / R_{I}<0.1 \\
& C_{I}=\sum_{j=1}^{n} a_{j} C_{I j} \quad R_{I}=\sum_{j=1}^{n} a_{j} R_{I j}
\end{aligned}
$$

When $\mathrm{CR}<0.1$, the consistency of judgment matrix is satisfied, otherwise,we need to adjust the judgment matrix, make it has satisfactory consistency.

After customer demand relation matrix has been built, through the result determines other matrix in HoQ to realize transmission and distribution from customer demand to PSS characteristic.
According to specific product service system extract technology features, and establish technical characteristics set which is expressed by $\mathrm{EC}_{\mathrm{s}}$. PSS contains the product Technical characteristics and service Technical characteristics. $\mathrm{EC}_{\mathrm{s}}$ contain $\mathrm{P}-\mathrm{EC}_{\mathrm{s}}$ (On behalf of product technical characteristics set) and $\mathrm{S}-\mathrm{EC}_{\mathrm{s}}(\mathrm{On}$ behalf of servicetechnical characteristics set).

$$
E C_{s}=\left\{E C_{1}, E C_{2}, \cdots, E C_{n+m}\right\}
$$

Establish correlation matrix between customer demand and technical characteristics, $R_{j k}$ is the correlation coefficient between $\mathrm{CR}_{\mathrm{j}}$ (on behalf of customer demand set) and $\mathrm{EC}_{\mathrm{k}}$. According the relation degree between customer demand and technical characteristics, express strong related, week related and un-related by $9,1,0$, then achieving matrix U. By using $-3,0,1,9$ express negative related, un-related, Positive correlation and autocorrelation, then achieving matrix $\mathrm{P}^{\prime}$ and $\mathrm{P}$ (standardization form of $\mathrm{P}$ '). At last, calculating relation matrix $\left(\mathrm{R}, \mathrm{r}_{\mathrm{ij}}\right.$ is coefficient in $\mathrm{R}$ ) between customer demand and technical characteristics, and its relative importance matrix V. 


$$
r_{i j}=\frac{\sum_{k=1}^{n}\left|u_{i k} p_{j k}\right|}{\sum_{j=1}^{n} \sum_{k=1}^{n}\left|u_{i k} p_{j k}\right|}=\frac{\sum_{k=1}^{n}\left|u_{i k} p_{k j}\right|}{\sum_{j=1}^{n} \sum_{k=1}^{n}\left|u_{i k} p_{k j}\right|}=\frac{\left|(U P)_{i j}\right|}{\sum_{j=1}^{n}\left|(U P)_{i j}\right|}
$$

According to the result above can solve standardization problem when transfer and distribute from customer demand to technical characteristics in the PSS design process, improve the accuracy and applicability whenusing CBR retrieve case.

\subsection{Optimization of PSS Design Result Based on GA}

In view of the current single PSS design result cannot meet the customer demand, second optimization based on process optimization design isproposed.Optimization design process of design result as follows.

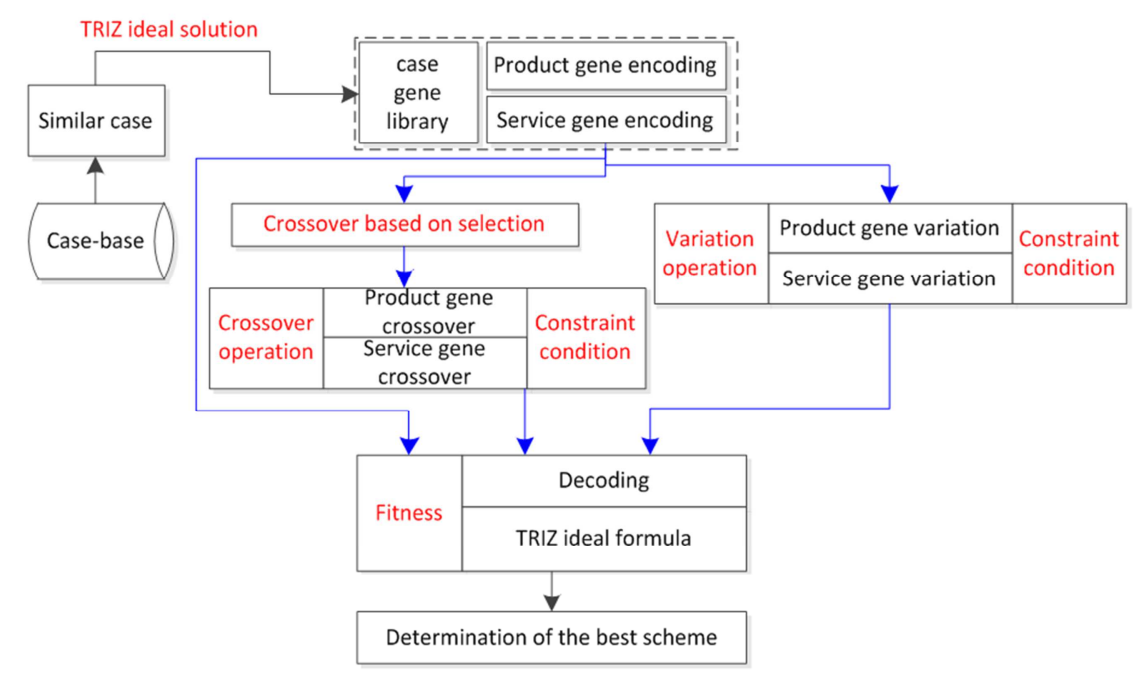

Fig. 3. Optimization design process of PSS based on GA.

Second optimization process is as follows:

(1) Based on products and services build PSS design genetic information as Fig.4 shown;

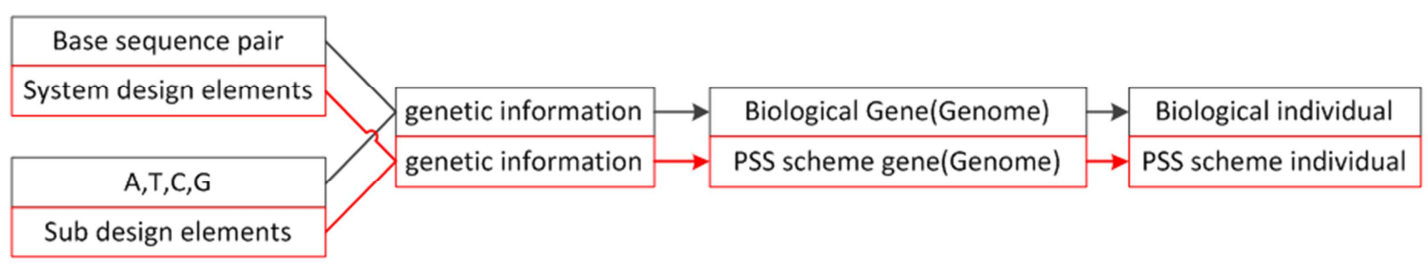

Fig. 4. Analogy between biological gene and PSS design.

(2) Combining TRIZ theory and coding method in GA to establish PSS coding method, implementing the mapping between phenotypes and genotypes of PSS;

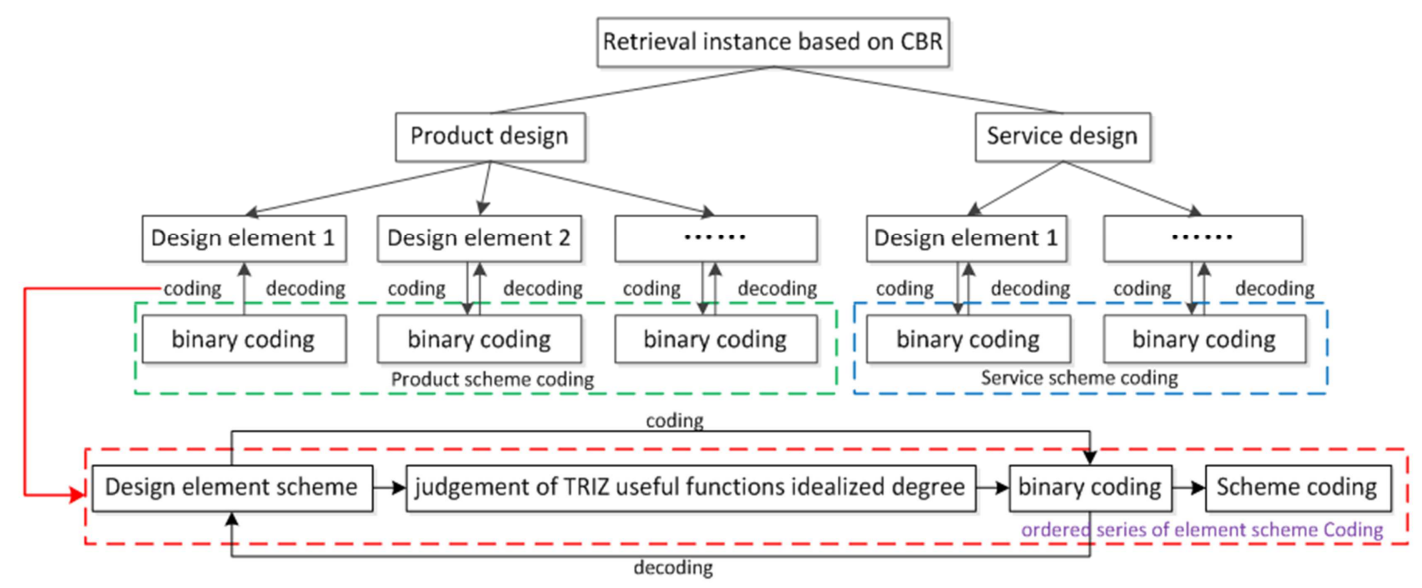

Fig. 5. Mapping method. 
Method to achieve PSS plan gene encoding is shown in Fig. 5. First, experts make judgmentsof scheme design elements such as $\Sigma$ Benefits, $\Sigma$ Expense, $\Sigma$ Harms idealized degree, and give each value. Then, transformthe useful function ideal degree value to binary coding, use the coding present PSS scheme; finally, take an orderly series of all design elements gene encoding as the genome characterization of PSS. For example, Value of $\Sigma$ Benefits is 5, its binary code is 101 .

Define $\Sigma$ Benefits, $\Sigma$ Expense, $\Sigma$ Harms idealized degree value is divided into seven levels, from 1 to 7 , the larger the value the deeper the degree, as shown in table 4 . Numerical converted to binary code as shown in table 5 .

Table 4. Factors value degree of ideal solution.

\begin{tabular}{l|l|l}
\hline Elements & Degree value & Significance \\
\hline$\Sigma$ Benefits & $1,2,3,4,5,6,7$ & Value from small to large, benefits degree turn high(+) \\
$\Sigma$ Expense & $1,2,3,4,5,6,7$ & Value from small to large,cost degree turn high $(-)$ \\
$\Sigma$ Harms & $1,2,3,4,5,6,7$ & Value from small to large,harms degreeturn high(-) \\
\hline
\end{tabular}

Table 5. Binary code conversion results.

\begin{tabular}{lllllll}
\hline Elements degree & $\mathbf{1}$ & $\mathbf{2}$ & $\mathbf{3}$ & $\mathbf{4}$ & $\mathbf{5}$ & $\mathbf{7}$ \\
\hline Binary coding & 001 & 010 & 011 & 100 & 101 & 110 \\
\hline
\end{tabular}

(3) In order to expand the optimization target space according to genetic manipulation and search in the space, access to numerous individual genome encodes in genetic space, decodingthese gene to obtain individual scheme; This process is realized by crossover and mutation.

Crossover:In the $\mathrm{N}$, free to choose two individuals take crossover operation, produce two new individuals, repeat this process until the completion of the individual crossover.

For example, get the new schemes by taking crossover operation between scheme 1 and scheme 2 in the underline.

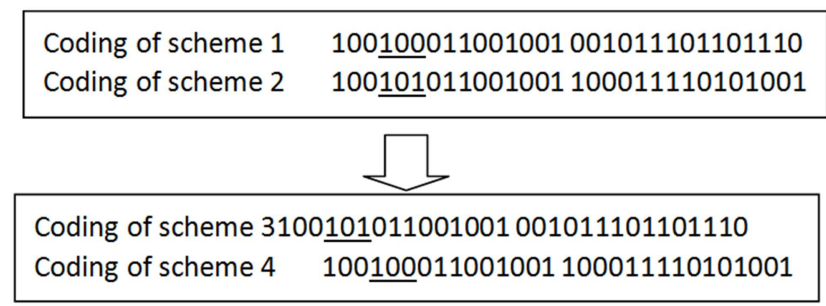

Mutation: It basic content is the gene value on gene string changes at certain mutation probability.

For example, in the underline take mutation operation can get new scheme.

\begin{tabular}{|ll|}
\hline Coding of scheme a & $10 \underline{0} 100011001001001011101101110$ \\
\hline Coding of scheme b & $10 \underline{1} 100011001001001011101101110$ \\
\hline
\end{tabular}

Finally, according toideal formula realize determination of the best scheme. Develop platform to assistdesigner complete optimization design of PSS.

$$
I=\sum \text { Benefits } /\left(\sum \text { Expense }+\sum \text { Harms }\right)
$$

\section{Validation}

The emergence of sewage treatment equipment makes urban sewage is no longer a waste, but a valuable resource that can be used. Sewage treatment equipment is shown as Fig. 6, it works as shown Fig. 7. The treated sewage can replace clean water, and reduce pollution emissions while saving the limited resources. In paper, through sewage treatment equipment optimization design verify the validity of the method.
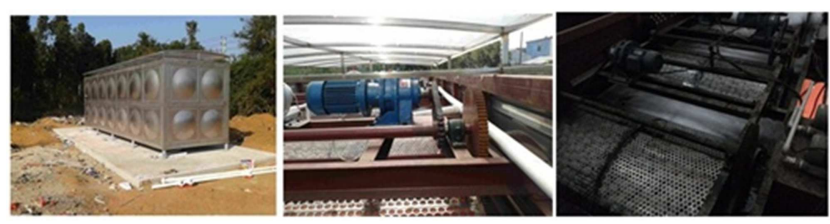

Fig. 6. Sewage treatment equipment.

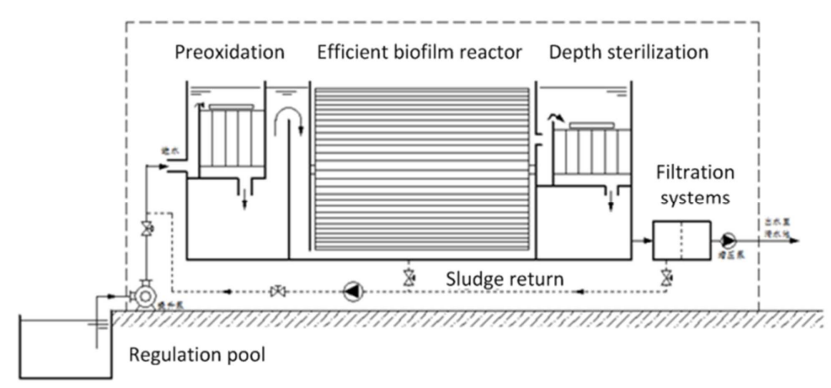

Fig. 7. Principle diagram of the sewage treatment equipment operation.

\subsection{Optimization of Sewage Treatment PSS Design Process}

Build HoQ:

Collect customer needs and determine the relative weights based on AHP. Customer needs as shown in table 6 .

Table 6. Relatively important degree of customer demand.

\begin{tabular}{lllllll}
\hline $\mathbf{A}$ & CR1 & CR2 & CR3 & CR4 & CR5 & CR6 \\
\hline CR1 & 1 & 2 & 3 & 5 & 7 & 7 \\
CR2 & $1 / 2$ & 1 & 2 & 4 & 6 & 6 \\
CR3 & $1 / 3$ & $1 / 2$ & 1 & 3 & 4 & 4 \\
CR4 & $1 / 5$ & $1 / 4$ & $1 / 3$ & 1 & 2 & 4 \\
CR5 & $1 / 7$ & $1 / 6$ & $1 / 4$ & $1 / 2$ & 1 & 1 \\
CR6 & $1 / 7$ & $1 / 6$ & $1 / 4$ & $1 / 2$ & 1 & 1 \\
\hline
\end{tabular}

Matrix A: 


$$
\begin{gathered}
A=\left[\begin{array}{cccccc}
1 & 2 & 3 & 5 & 7 & 7 \\
1 / 2 & 1 & 2 & 4 & 6 & 6 \\
1 / 3 & 1 / 2 & 1 & 3 & 4 & 4 \\
1 / 5 & 1 / 4 & 1 / 3 & 1 & 2 & 4 \\
1 / 7 & 1 / 6 & 1 / 4 & 1 / 2 & 1 & 1 \\
1 / 7 & 1 / 6 & 1 / 4 & 1 / 2 & 1 & 1
\end{array}\right] \\
\lambda_{\max }=6.272 \text { C.I. }=\frac{6.272-6}{6-1}=0.054 \\
C . R .=\frac{C . I .}{R . I .}=\frac{0.054}{1.26}=0.043<0.1 \\
W=(0.394,0.266,0.166,0.088,0.043,0.043)^{T}
\end{gathered}
$$

Determine the correlation matrix between customer needs and technical characteristics, and calculates relative weight.

$$
U=\left[\begin{array}{llllllll}
9 & 9 & 0 & 0 & 1 & 0 & 0 & 0 \\
9 & 0 & 0 & 0 & 1 & 0 & 0 & 0 \\
9 & 9 & 9 & 1 & 1 & 1 & 1 & 0 \\
1 & 0 & 0 & 0 & 0 & 0 & 0 & 0 \\
0 & 0 & 0 & 0 & 0 & 9 & 0 & 0 \\
0 & 0 & 0 & 0 & 9 & 0 & 0 & 0
\end{array}\right]
$$

$V=(0.300,0.154,0.063,0.003,0.086,0.117,0.127,0.149)^{T}$

Sewage treatment PSS HoQ is shown as Fig.8.

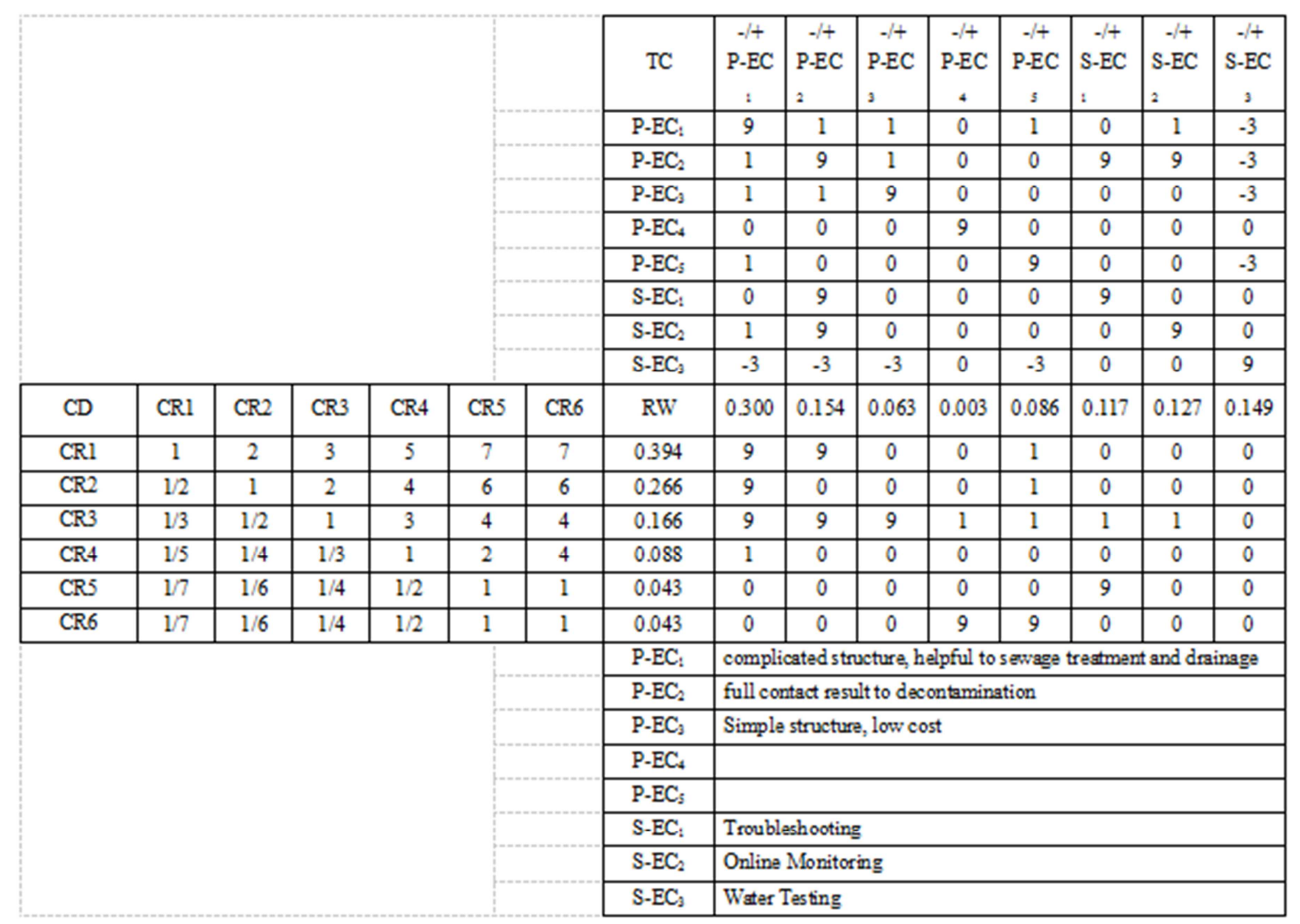

Fig. 8. HoQ of sewage treatment PSS.

$$
P^{\prime}=\left[\begin{array}{cccccccc}
9 & 1 & 1 & 0 & 1 & 0 & 1 & -3 \\
1 & 9 & 1 & 0 & 0 & 9 & 9 & -3 \\
1 & 1 & 9 & 0 & 0 & 0 & 0 & -3 \\
0 & 0 & 0 & 9 & 0 & 0 & 0 & 0 \\
1 & 0 & 0 & 0 & 9 & 0 & 0 & -3 \\
0 & 9 & 0 & 0 & 0 & 9 & 0 & 0 \\
1 & 9 & 0 & 0 & 0 & 0 & 9 & 0 \\
-3 & -3 & -3 & 0 & -3 & 0 & 0 & 9
\end{array}\right]
$$$$
P=\left[\begin{array}{cccccccc}
1 & 0.11 & 0.11 & 0 & 0.11 & 0 & 0.11 & -0.33 \\
0.11 & 1 & 0.11 & 0 & 0 & 1 & 1 & -0.33 \\
0.11 & 0.11 & 1 & 0 & 0 & 0 & 0 & -0.33 \\
0 & 0 & 0 & 1 & 0 & 0 & 0 & 0 \\
0.11 & 0 & 0 & 0 & 1 & 0 & 0 & -0.33 \\
0 & 1 & 0 & 0 & 0 & 1 & 0 & 0 \\
0.11 & 1 & 0 & 0 & 0 & 0 & 1 & 0 \\
-0.33 & -0.33 & -0.33 & 0 & -0.33 & 0 & 0 & 1
\end{array}\right]
$$

$\left[\begin{array}{llllllll}0.205 & 0.203 & 0.040 & 0 & 0.040 & 0.182 & 0.203 & 0.127\end{array}\right]$

$\begin{array}{llllllll}0.524 & 0.057 & 0.057 & 0 & 0.115 & 0 & 0.057 & 0.190\end{array}$

$R=$ $\begin{array}{llllllll}0.565 & 0.062 & 0.062 & 0 & 0.062 & 0 & 0.062 & 0.186\end{array}$

$\begin{array}{llllllll}0 & 0.5 & 0 & 0 & 0 & 0.5 & 0 & 0\end{array}$

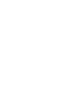


According the Fig. 8 above, realize the mapping between customer needs and technical characteristics. The result as follows:

Good performance at dirt (CR1) - box and basket (activated carbon, electrolysis, stirring rod, etc.);

Discharge performance and generation of impurities (CR2) - housing and into the drainage system (electrolysis, sewage plant);

Cost (CR3) - cage and drive (wheels, rack, and transmission mode);

Water (CR4) - Water Testing Services;

Device Status (CR5) - Online Monitoring Service.

\subsection{Optimization of Sewage Treatment PSS Design Result}

From the above results, Search case by CBR. The results are as follows.

Scheme 1:

Cabinet: pre-oxidation part use activated carbon to treat sewage, and directly open the overflow hole.Depth sterilization part uses the electrolysis apparatus to realize sterilization of sewage treatment equipment;

Caged: caged internal skeleton equipped with a stirring rod, inner hub slot, full useful access sewage to decontamination devices, rack use plastic materials to reduce costs;

Gear: complete transmission (unilateral) by engaging between the gears;

Service: Remote Troubleshooting (motor shaft), real-time online monitoring (caged speed, water pulse, noise), water quality testing.

Scheme 2

Cabinet: pre-oxidation part use activated carbon and electrolysis apparatus to treat sewage treatment, and usetriangle cofferdam method connected with the efficient biofilm reactor. Depth sterilization section use electrolysis apparatus to treat sewage meanwhile. Install sewage plant beside electrolysis apparatus (electrolytic process will produce large amounts of impurities).

Caged: caged internal skeleton equipped with a stirring rod, wheels are not slotted, full useful access sewage to decontamination devices, rack made of carbon steel materials by line cutting.

Transmission: gear (bilateral).

Service: Remote Troubleshooting (motor), real-time online monitoring (water pulse, equipment), water quality testing.

Scheme 3

Cabinet: pre-oxidation part use activated carbon to treat sewage, and usetriangle cofferdam method to connect with the efficient biofilm reactor, while inside pre-oxidation part use the draft tube to connect simultaneously. Depth sterilization section use electrolysis apparatus for the sewage treatment equipment, and equipped with infrared depth sterilization.

Caged: caged internal skeleton equipped with a stirring rod, wheels are not slotted, full useful access sewage to decontamination devices, rack use plastic materials to reduce costs;

Transmission: gear (bilateral).
Service: Remote Troubleshooting (motor shaft), real-time online monitoring (noise, equipment, shaft speed, water pulse), water quality testing.

Make judgments of design elements ideal degree in system, as table 7 shown.

Table 7. Ideal value degree of expert judgment.

\begin{tabular}{lllll}
\hline & Scheme & Benefit & Harm & Cost \\
\hline \multirow{3}{*}{ Case } & 1 & 3 & 1 & 2 \\
& 2 & 4 & 1 & 2 \\
Caged & 3 & 5 & 1 & 3 \\
& 1 & 5 & 2 & 3 \\
transmission & 2 & 4 & 3 & 5 \\
& 3 & 3 & 4 & 2 \\
control & 2 & 3 & 1 & 3 \\
& 3 & 2 & 3 & 5 \\
Into the & 1 & 2 & 3 & 5 \\
drainage & 2 & 1 & 1 & 1 \\
& 3 & 1 & 1 & 1 \\
Remote & 1 & 1 & 1 & 1 \\
Diagnosis & 3 & 3 & 2 & 4 \\
& 1 & 3 & 3 & 3 \\
Online & 3 & 3 & 3 & 3 \\
Monitoring & 2 & 2 & 2 & 4 \\
Installation & 3 & 3 & 4 & 3 \\
and & 1 & 3 & 2 & 4 \\
maintenance & 3 & 5 & 3 & 3 \\
\hline
\end{tabular}

Coding result is shown as Table 8 .

Table 8. Sewage treatment product service system genes encoding.

\begin{tabular}{lll}
\hline & & Sewage treatment PSS scheme gene coding \\
\hline \multirow{2}{*}{ Scheme 1 } & Degree & 35315331 \\
& Coding & 011101011001101011011001 \\
Scheme 2 & Degree & 44213221 \\
& Coding & 100100010001011010010001 \\
Scheme 3 & $\begin{array}{l}\text { Degree } \\
\text { Coding }\end{array}$ & 53213351 \\
& & 101011010001011011101001 \\
\hline
\end{tabular}

Take genetic manipulation between the 3 Schemes gene coding above, and get on optimal decision, the results are as table 9 .

Table 9. Calculation result of PSS Idealized level.

\begin{tabular}{lllllll}
\hline Scheme & $\mathbf{I}_{\mathbf{1}}$ & $\mathbf{I}_{\mathbf{2}}$ & $\mathbf{I}_{\mathbf{3}}$ & $\mathbf{I}_{\mathbf{4}}$ & $\mathbf{I}_{\mathbf{5}}$ & $\mathbf{I}_{\mathbf{6}}$ \\
\hline Ideal degree & 0.61 & 0.59 & 0.62 & 0.64 & 0.63 & 0.7 \\
Scheme & $\mathrm{I}_{7}$ & $\mathrm{I}_{8}$ & $\mathrm{I}_{9}$ & $\mathrm{I}_{10}$ & $\mathrm{I}_{11}$ & $\mathrm{I}_{12}$ \\
Ideal degree & 0.67 & 0.61 & 0.65 & 0.59 & 0.69 & 0.71 \\
Scheme & $\mathrm{I}_{13}$ & $\mathrm{I}_{14}$ & $\mathrm{I}_{15}$ & $\mathrm{I}_{16}$ & $\mathrm{I}_{17}$ & $\ldots$ \\
Ideal degree & 0.72 & 0.67 & 0.66 & 0.63 & 0.68 & $\ldots$ \\
\hline
\end{tabular}

The best scheme ideal degree value is 0.72 . It corresponds to the program is as follows:

Cabinet: pre-oxidation part use activated carbon adsorption to treat sewage, while opening the overflow hole and install the draft tube to achieve connectivity efficiently between pre-oxidation and biofilm reactor. Depth sterilization part use 
electrolysis apparatus to realize sterilization of sewage treatment systems, meanwhile equipped with infrared depth sterilization.

Caged: caged internal skeleton equipped with a stirring rod, inner hub slot, full useful access sewage to decontamination devices, rack plastic materials usedto reduce costs.

Gear: the motor driven reduction gear engage.

Service: Remote Troubleshooting (motor shaft), real-time online monitoring (caged speed, water pulse, noise, equipment), water quality testing.

Compare the optimized scheme with un-optimized scheme, Optimized scheme not only meet customer needs, while reducing costs, the decontamination and sewage effect of equipment significantly improved. The original generation of impurities will be removed without affecting decontamination equipment in the electrolysis process. Provide the water quality monitoring online monitoring and other services have improved the competitiveness of Sewage treatment product service system.

\section{Conclusion}

Based on genetic algorithm and QFD to break the conventional PSS design limitations to obtain more in line with the requirements of the design, the PSS design to binary genes encoding mapping method is put forward, with the evolution of the binary code of evolutionary operation system characterization scheme. TRIZ ideal solution as the objective function to determine the optimal solution, to achieve the optimal solution; this paper draw on the genetic algorithm and QFD, combined with examples, to solve the problem in the system design optimization design:

(1) An optimization of product service system design scheme based on QFD.

(2) Based on the theory of evolution broke the limitations of conventional PSS design, through evolutionary operation obtain more in line with the requirements of the design, in the evolutionary process according to the needs of designers determine the evolutionary position, in order to guarantee the validity of system evolution and avoid a large number of design data cannot deal with the situation, in order to facilitate the selection of the optimal solution;

(3) PSS design to binary genes encoding mapping method is proposed to by binary coding in evolutionary operation characterization of changes in PSS design evolution, method is simple, intuitive, logical relationship clear, easy to processing of large amount of data in the form of data;
(4) Using TRIZ ideal solution as the objective function to obtain optimal design solution.

Fully proving the optimization method is very effective in PSS design, and providing a good guidance significance to other PSS designers.

\section{References}

[1] E. Sundin, B. Bras, Making functional sales environmentally and economicallybeneficial through product remanufacturing, J. Clean. Prod. 13 (9) (2005)913-925.

[2] J. Lindstro "m, M. Lo fstrand, M. Karlberg, L. Karlsson, A development process forfunctional products: hardware, software, service support system andmanagement of operation, Int. J. Prod. Dev. 16 (3) (2012) 284-303.

[3] Min Qu, Suihuai Yu, Dengkai Chen, Jianjie Chu, BaozhenTian, State-of-the-art of design, evaluation, and operation methodologies inproduct service systems. Computers in Industry 77 (2016) 1-14.

[4] Mont O, Clarifying the concept of product service system [J]. Cleaner Production, 2002, 3(10):237-245.

[5] Mont O, Product-service systems: Panacea or myth?[J]. Doctoral Dissertation, 2004, LundUniversity, Sweden.

[6] Tukker Arnold. Eight types of product-service system: eight ways to sustainability? Experiencefrom suspronet[J]. Business Strategy and the Environment, 2004, 13:246-260.

[7] Sakao T, Lindahl M. Introduction/Service-system Design[M]. [s.l.]: Spring Verlag, 2009.

[8] SUNDIN E, LINDAHL M, IJOMAH W. Product design for product/service systems: Designexperience from Swedish industry[J]. Journal of Manufacturing Technology Management, 2009, 20(5):723-753.

[9] David BL, Andrew K. Case-Based CBR: capturing and reusing reasoning about case adaptation [J].International Journal of Expert Systems, 1997, 10(2):201-215.

[10] Wasserman, X. P., Bode, J., Ren, S. J. Neural networks in quality function deployment. Computers and Industrial Engineering. 1996, 31(3/4): 669-673.

[11] Lu, M. H., Madu, C. N., Kuei, C. and Winokur, D. Integrating QFD, AHP and benchmarkingin strategic marketing. Journal of Business \& Industrial Marketing. 1994, 9(1): 41-50.

[12] Hui Liang, Jun Zhou, Sustainable development of product service system design based on analytic hierarchy process. International Journal of Research in Engineering and Science (IJRES). 2015, 3(5):1-8. 